\title{
IMPROVING THE CORROSION RESISTANCE OF AZ31 MAGNESIUM ALLOY BY PREPARING HYDROXYAPATITE WITH A SUPERHYDROPHOBIZED SURFACE
}

\author{
Jiří HONČ, Martin BUCHTíK, Jaromír WASSERBAUER, Leoš DOSKOČIL \\ Brno University of Technology, Faculty of Chemistry, Brno, Czech Republic, EU, doskocil@fch.vut.cz
}

https://doi.org/10.37904/metal.2021.4171

\begin{abstract}
Magnesium and its alloys are promising materials that have potential mainly in the field of transport (e.g. automobile industry) and medicine (e.g. orthopedic implants). Their disadvantage is poor corrosion resistance, which limits their wider use in practice. Therefore, surface treatment by various methods is performed in order to improve corrosion protection. The preparation of a superhydrophobic coating is an interesting approach because the hydrophobic coating minimizes contact of the corrosion medium with the magnesium substrate. In this work, the hydrothermally prepared hydroxyapatite coating on AZ31 magnesium alloy was superhydrophobized by myristic acid. The prepared coatings were characterized by determining contact angle and surface analysis using a scanning electron microscopy with energy dispersive spectroscopy and Fourier transformed infrared spectroscopy. The corrosion resistance of modified surfaces was examined by potenciodynamic polarization in $3.5 \% \mathrm{NaCl}$.
\end{abstract}

Keywords: Corrosion, AZ31 magnesium alloy, hydroxyapatite coating, superhydrophobization

\section{INTRODUCTION}

Magnesium is a lightweight metal with superior strength to weight ratio and excellent damping capacity. It has a great potential to be used in automotive industry, aeronautics etc. [1]. Magnesium alloys have been also widely studied for biodegradability and biocompatibility, as they could be used for biomedical applications [2]. A poor corrosion resistance is the biggest limiting factor for its wider use. $\mathrm{Mg}$ alone easily oxidizes in common environments due to the highly negative electrode potential. While some alloying elements can improve corrosion resistance, others may worsen it as a microcell corrosion between different phases can occur [3]. Moreover, the hydroxides and oxides produced by corrosion are uneven and loose. They cannot protect magnesium substrate from further deterioration, especially in the presence of $\mathrm{Cl}^{-}[4]$.

Many surface treatments and protective coatings have been studied, including fluoride conversion coatings, micro arc oxidation (MAO), electroless deposition of Ni-P coatings, physical/chemical vapour deposition etc. $[5,6,7]$. One promising approach to corrosion protection is the use of hydroxyapatite $(\mathrm{HA})$ coatings [5].

Hydroxyapatite $\left(\mathrm{HA} ; \mathrm{Ca}_{5} \mathrm{OH}\left(\mathrm{PO}_{4}\right)_{3} / \mathrm{Ca}_{10}\left(\mathrm{PO}_{4}\right)_{6}(\mathrm{OH})_{2}\right)$ is biocompatible material naturally occurring in teeth and bones, which makes it perfectly suitable for implants. There are several studied methods of HA preparation, such as sol-gel process, electro-deposition, and hydrothermal treatment. Properties and morphology of HA coating varies in dependence on used method [8-9]. The electrodeposition is usually realized by direct continuous or pulsed current, while the latter method provides better results [10]. The hydrothermal treatment is simple and cost-effective technique of HA production, but it needs chemical activation of magnesium surface to achieve better adhesion. The simplest way to improve adhesion is the alkaline surface conversion of magnesium to $\mathrm{Mg}(\mathrm{OH})_{2}$. Recently, phytic acid and glucose have also been used successfully. [11-12].

The corrosion resistance of magnesium alloys may be also improved by preventing contact of the corrosive medium with the substrate. This protection strategy can be achieved by introducing superhydrophobicity [4]. Superhydrophobicity is characterized by water contact angles higher than $150^{\circ}$ and sliding angle lower than 
$10^{\circ}$. Common surface modifying agents are unable to produce flat surface with contact angle larger than $120^{\circ}$. Therefore, further increasement of contact angle can be done by implementing surface roughness. For creation of favourable surface structure, many different methods are currently studied [13].

The idea of HA hydrophobization was already examined by some researchers [14]. Kang et al. (2018) describes one-step hydrothermal fabrication of superhydrophobic hydroxyapatite which was achieved by utilization of ratio between water solution of HA precursors and ethanol solution of stearic acid. Although the corrosion current in Hank solution measured by potentiodynamic polarization was improved by four magnitudes, the article does not provide any information about the long-term stability [15].

This work deals with hydrothermal preparation of hydroxyapatite which is then superhydrophobized with myristic acid by electrodeposition. Special emphasis was placed on the corrosion behavior in $3.5 \% \mathrm{NaCl}$ using electrochemical tests including potentiodynamic polarization and electrochemical impedance spectroscopy.

\section{MATERIAL AND METHODS}

The AZ31 magnesium alloy was used for experiments. The chemical composition was determined using glowdischarge optical emission spectroscopy (GDOES) on a Spectrumat GDS 750 instrument (Spectruma Analytik $\mathrm{GmbH}, \mathrm{Hof}, \mathrm{Germany)}$. The values are listed in Table 1. The material was cut into samples with a size of 20 $\times 20 \times 5 \mathrm{~mm}$. It was abraded with silicon carbide papers of 600 and 1200 grit, rinsed with water and isopropanol and dried by hot air.

Table 1 Chemical composition of used magnesium alloy AZ31.

\begin{tabular}{|c|c|c|c|c|c|c|c|}
\hline \multirow{2}{*}{ Alloy } & \multicolumn{7}{|c|}{ Chemical composition (wt\%) } \\
\cline { 2 - 8 } & $\mathrm{Al}$ & $\mathrm{Zn}$ & $\mathrm{Mn}$ & $\mathrm{Si}$ & $\mathrm{Fe}$ & $\mathrm{Sn}$ & Balance \\
\hline AZ31 & 3.60 & 1.34 & 0.28 & 0.03 & 0.002 & 0.01 & 94.738 \\
\hline
\end{tabular}

Square coupons were placed in a hydrothermal reactor for $12 \mathrm{~h}$ at $120^{\circ} \mathrm{C}$ which contained $150 \mathrm{ml}$ of $2 \mathrm{~mol} / /$ $\mathrm{NaOH}$. This surface treatment resulted in the formation of magnesium hydroxide which served as a base layer for better HyA adhesion.

The preparation of hydroxyapatite was as follows: $125 \mathrm{ml}$ of a solution containing $2 \mathrm{~g}$ of dissolved ammonium dihydrogen phosphate was added dropwise to $175 \mathrm{ml}$ of a solution in which $6 \mathrm{~g}$ of $\mathrm{Ca}\left(\mathrm{NO}_{3}\right)_{2} \cdot 4 \mathrm{H}_{2} \mathrm{O}$ was dissolved. During the dropwise addition, the solution was stirred vigorously and the $\mathrm{pH}$ was adjusted to 4.5 using $\mathrm{NaOH}$ solution. The AZ31 alloy coated with the $\mathrm{Mg}(\mathrm{OH})_{2}$ was placed in an autoclave for $2 \mathrm{~h}$ at $120^{\circ} \mathrm{C}$. The prepared hydroxyapatite was rinsed with water and isopropanol and then dried with hot air.

Superhydrophobization of the hydroxyapatite coated sample was performed by electrodeposition. The calcium nitrate $(0.01 \mathrm{~mol} / \mathrm{l})$ and myristic acid $(0.1 \mathrm{~mol} / \mathrm{l})$ were added into $175 \mathrm{ml}$ of $90 \mathrm{vol}$. \% ethanol. Sample was placed in the prepared solution as the cathode and a plain AZ31 plate $(20 \times 20 \times 5 \mathrm{~mm})$ was as the anode. The two electrodes were $2 \mathrm{~cm}$ apart. Direct current source (Diametral, P130R51D, Czech Republic) was employed under a voltage of $30 \mathrm{~V}$ for $20 \mathrm{~min}$. The superhydrophobized samples were rinsed with isopropanol and then dried with hot air.

The water contact angle was measured using Contact Angle System OCA (DataPhysiscs instruments). The volume of each water drop was about $5 \mu \mathrm{l}$.

Electrochemical measurements were carried out using VSP-300 potentiostat. Conventional three electrodes glass cell was used with platinum counter electrode, saturated calomel electrode as reference electrode with Luggin capillary bridge and sample with geometric area $1 \mathrm{~cm}^{2}$ as working electrode. The potentiodynamic polarization curves were recorded in the range of $-200 \mathrm{mV}$ to $400 \mathrm{mV}$ vs. open circuit potential at a scanning rate of $1 \mathrm{mV} / \mathrm{s}$. Before recording the polarization curves, the open circuit potential was stable within 30 min. 
Measurements were performed in environment of $3.5 \% \mathrm{NaCl}$ at room temperature for the plain $\mathrm{AZ31}$, the AZ31 with hydroxyapatite coating $\left(\mathrm{HA} / \mathrm{Mg}(\mathrm{OH})_{2} / \mathrm{AZ31}\right)$ and the superhydrophobized $\mathrm{AZ31}\left(\mathrm{Myr} / \mathrm{Mg}(\mathrm{OH})_{2} / \mathrm{AZ31}\right)$.

Fourier-transform infrared (FTIR) spectra of myristic acid and superhydrophobic coating were obtained in Attenuated Total Reflection (ATR) mode using a Nicolet iS10 spectrometer. Spectrum was recorded over the range $3000-500 \mathrm{~cm}^{-1}$ at $2 \mathrm{~cm}^{-1}$ resolution and was the averages of 68 scans. The spectrum for air on a clean dry ATR diamond crystal was used as the background for the infrared measurements. The morphology and elemental composition of the superhydrophobic coating were analyzed using a Zeiss EVO LS-10 scanning electron microscope (SEM) (Carl Zeiss Ltd., Cambridge, UK) with energy-dispersive spectroscopy (EDS), an Oxford Instruments Xmax $80 \mathrm{~mm} 2$ detector (Oxford Instruments plc, Abingdon, UK) and AZtec software (version 2.4, Oxford Instruments, High Wycombe, UK).

\section{RESULTS ANF DISCUSSION}

Surface analysis using SEM did not reveal a visible change in the surface morphology of the AZ31 alloy after treatment in $2 \mathrm{~mol} / \mathrm{l} \mathrm{NaOH}$. The surface was flat and relatively smooth except for some polishing scratches, see Figure 1A. The hydroxyapatite layer deposited on $\mathrm{Mg}(\mathrm{OH})_{2} / \mathrm{AZ31}$ was characterized by a flower-like structure that was composed of smooth platelet crystals, see Figure 1B. The experience of the authors of this paper shows that hydroxyapatite forms more readily and with greater adhesion to the surface when AZ31 alloy is pretreated in sodium hydroxide.

The prepared hydroxyapatite was superhydrophobized using electrodeposition in a mixed solution of myristic acid and calcium nitrate in 90 vol.\% ethanol. Optimal conditions for electrodeposition included voltages of 30 $\mathrm{V}$ and $20 \mathrm{~min}$. A time longer than $20 \mathrm{~min}$ led to the formation of a thick layer which showed low adhesion to the surface. On the contrary, the shorter electrodeposition time did not allow the preparation of a coating with a superhydrophobic character.

The presence of water in the ethanol solution was also important because the absence of water or its low amount did not lead to the formation of a superhydrophobic coating in a reasonable time. On the other hand, the high water content caused a large number of hydrogen bubbles to block the binding of myristate to the surface. The long electrodeposition time and/or high water content resulted in dimples in the superhydrophobic coating visible to the eye. These traces were caused by the temporary surface adsorption of hydrogen bubbles that were released during electrodeposition due to the cathodic reaction of the magnesium substrate.
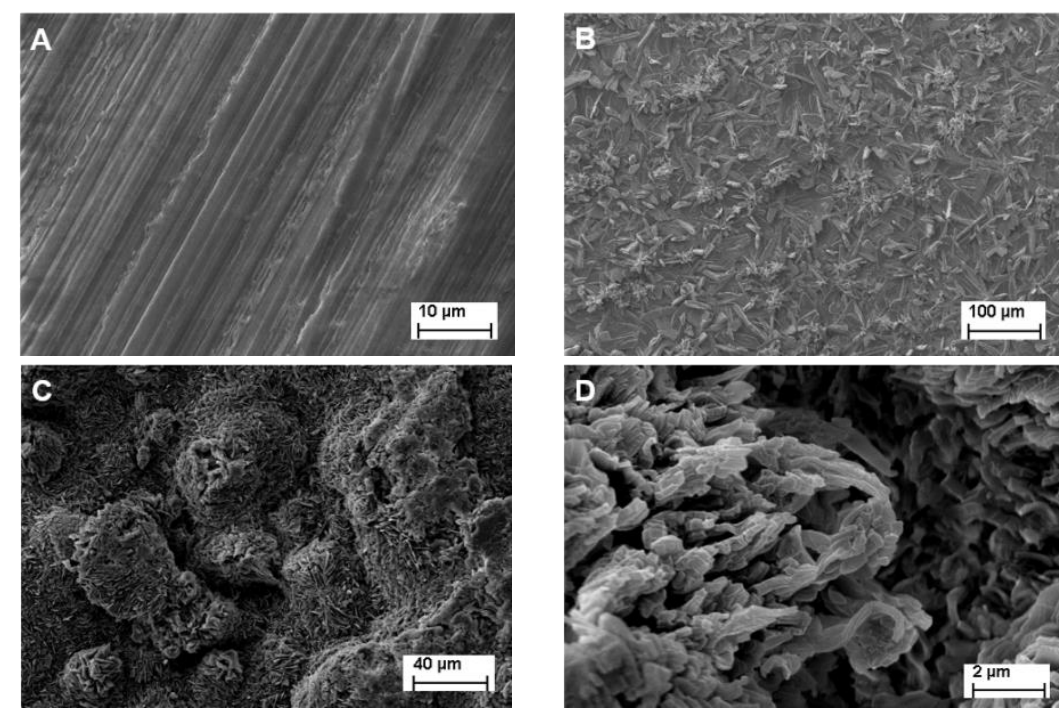

Figure $1 \mathrm{SEM}$ analysis of $\mathrm{Mg}(\mathrm{OH})_{2} / \mathrm{AZ31}(\mathrm{A}), \mathrm{HA} / \mathrm{Mg}(\mathrm{OH})_{2} / \mathrm{AZ31}$ (B), $\mathrm{Myr} / \mathrm{HA} / \mathrm{Mg}(\mathrm{OH})_{2} / \mathrm{AZ31}$ (C,D). 
The surface of the hydroxapatite was compactly covered with a superhydrophobic coating which consisted of flat and irregular shape, see (Figures 1C-D). The prepared coating had a contact water angle of $150.7 \pm 0.3^{\circ}$ and a sliding angle of about $7^{\circ}$. The surface of hydroxyapatite and $\mathrm{Mg}(\mathrm{OH})_{2}$ were hydrophilic.

The FTIR spectrum (Figure 2) of the superhydrophobized coating clearly revealed the presence of myristate. The spectrum contained two strong bands around 1550 and $1420 \mathrm{~cm}^{-1}$ which indicate asymmetric and symmetric valence vibrations of carboxylates. The long hydrocarbon chain of myristate was indicated by bands $3000-2800 \mathrm{~cm}^{-1}$ and $715 \mathrm{~cm}^{-1}$. The figure also shows the FTIR spectrum of myristic acid, which contains a characteristic band $1700 \mathrm{~cm}^{-1}$ corresponding to carboxyl groups.

Elemental analysis using EDS showed that the coating contained an average of 84.0 at\% carbon, 11.1 at\% oxygen and 4.9 at\% calcium. With regard to FTIR analysis, it can be assumed that the coating consists of calcium myristate.

The potentiodynamic polarization curves of samples are given in Figure 3. AZ31 alloy had the lowest corrosion resistance compared to other samples examined. The preparation of hydroxyapatite significantly improved the corrosion properties because the potentiodynamic curve shifted to lower values of the corrosion current. However, the surface treatment did not affect the corrosion potential $(-1.45 \mathrm{~V})$. Superhydrophobization resulted in a shift of the corrosion potential to more positive values and a significant reduction in the corrosion current density ( $\left.i_{c o r}\right)$. The value of $i_{c o r}$ decreased from $18.45 \mu \mathrm{A} / \mathrm{cm}^{2}$ for AZ31 to $0.05 \mu \mathrm{A} / \mathrm{cm}^{2}$ for $\mathrm{Myr} / \mathrm{HA} / \mathrm{Mg}(\mathrm{OH})_{2} / \mathrm{AZ31}$, showing a decrease of three orders of magnitude. These changes indicate that superhydrophobization provided excellent corrosion resistance. The formed coating effectively prevented the contact of the corrosive environment with the surface of the AZ31 alloy.

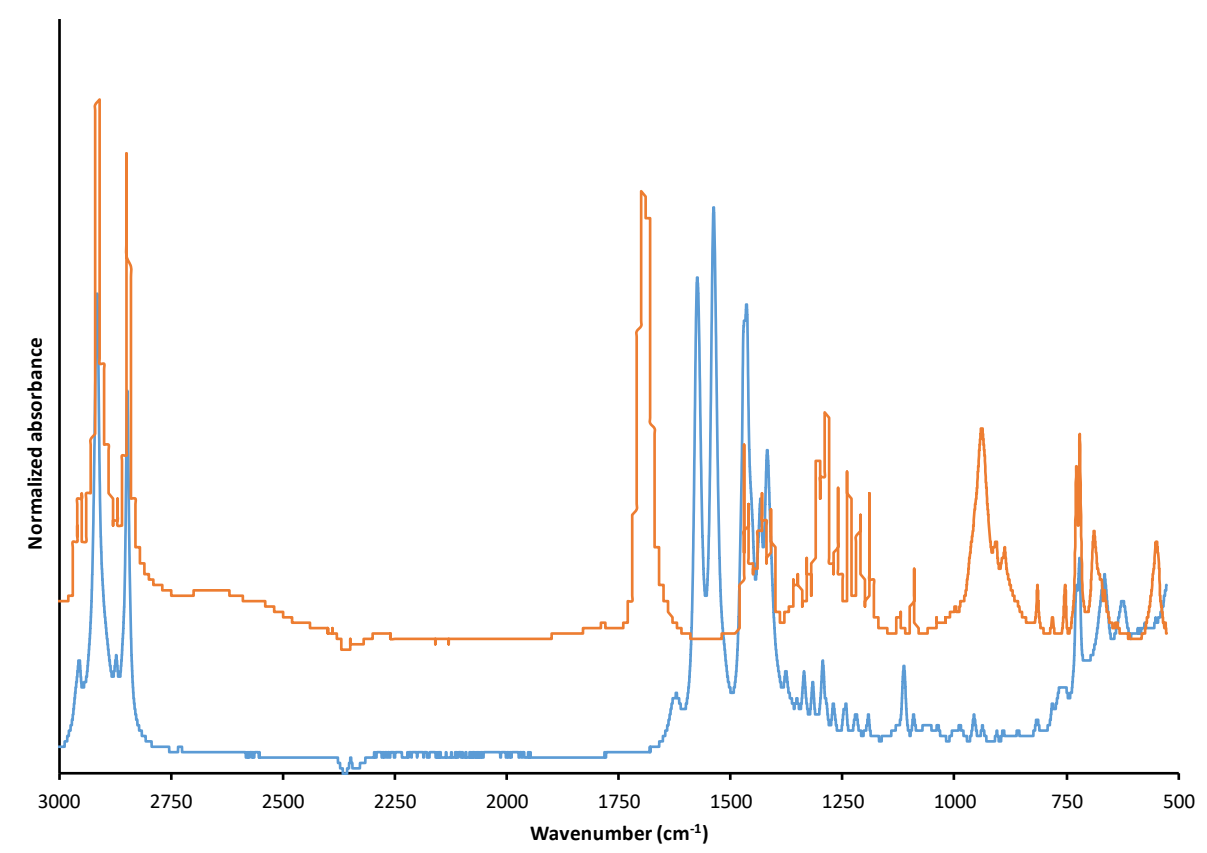

Figure $1 \mathrm{FTIR}$ spectra of myristic acis (orange) and superhydrophobized coating on $\mathrm{HA} / \mathrm{Mg}(\mathrm{OH})_{2} / \mathrm{AZ3} 1$ (blue).

Table 2 Parameters of PD measurements.

\begin{tabular}{|c|c|c|c|}
\hline & $\mathrm{AZ31}$ & $\mathrm{HA} / \mathrm{Mg}(\mathrm{OH})_{2} / \mathrm{AZ31}$ & $\mathrm{Myr} / \mathrm{HA} / \mathrm{Mg}(\mathrm{OH})_{2} / \mathrm{AZ31}$ \\
\hline $\mathrm{E}_{\mathrm{cor}}(\mathrm{V})$ & -1.45 & -1.45 & -1.35 \\
\hline $\mathrm{i}_{\mathrm{cor}}\left(\mu \mathrm{A} / \mathrm{cm}^{2}\right)$ & 18.45 & 0.23 & 0.05 \\
\hline
\end{tabular}




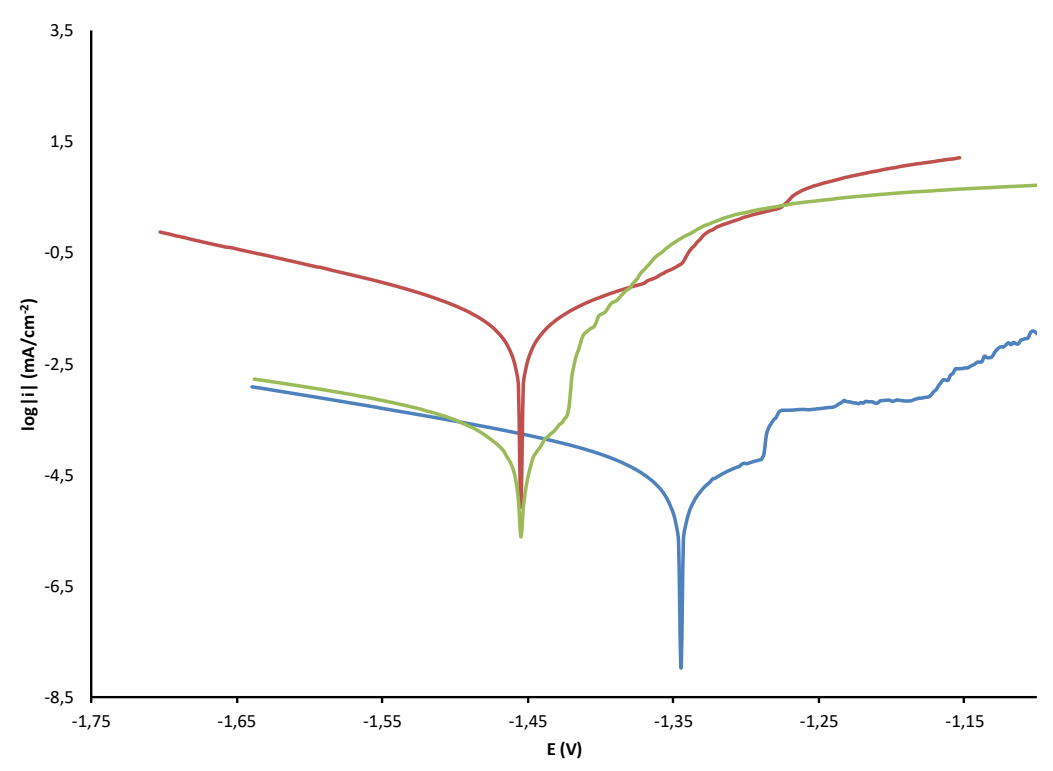

Figure 1 Potentiodynamic polarization curves of the $A Z 31$ alloy (red), the $\mathrm{HA} / \mathrm{Mg}(\mathrm{OH})_{2} / \mathrm{AZ31}$ alloy (green) and the superhydrophobized $\mathrm{HA} / \mathrm{Mg}(\mathrm{OH})_{2} / \mathrm{AZ} 31$ alloy (blue).

\section{CONCLUSION}

Hydroxyapatite was prepared by hydrothermal reaction on AZ31 alloy, on which the layer of $\mathrm{Mg}(\mathrm{OH})_{2}$ was previously formed. This treatment improved the corrosion properties of AZ31 alloy in a 3.5\% $\mathrm{NaCl}$ environment. Corrosion resistance improved significantly after superhydrophobization with myristic acid. The corrosion current density decreased by three orders of magnitude compared to the AZ31 alloy. Superhydrophobization was performed by electrodeposition under optimally selected conditions.

\section{ACKNOWLEDGEMENTS}

This work was supported by Specific University Research at FCH BUT, Project Nr. FCH-S-21-7553, Ministry of Education, Youth and Sports of the Czech Republic.

\section{REFERENCES}

[1] SONG, Jiangfeng, SHE, Jia, CHEN, Daolun a PAN, Fusheng. Latest research advances on magnesium and magnesium alloys worldwide. Journal of Magnesium and Alloys. [online]. 2020, vol 8, no. 1, pp. 1-41. Available from: https://doi.org/10.1016/j.jma.2020.02.003.

[2] RAHMAN, Mostafizur, DUTTA, Naba K. a CHOUDHURY, Namita ROY. Magnesium Alloys with Tunable Interfaces as Bone Implant Materials. Frontiers in Bioengineering and Biotechnology. [online]. 2020, vol. 8. Available from: https://doi.org/10.3389/fbioe.2020.00564.

[3] NEIL, W.C., FORSYTH, M., HOWLETT, P.C., HUTCHINSON, C.R. a HINTON, B.R.W. Corrosion of magnesium alloy ZE41 - The role of microstructural features. Corrosion Science. [online]. 2009, vol. 51, no.2, pp. 387-394. Available from: https://doi.org/10.1016/j.corsci.2008.11.005.

[4] PENG, Feng, ZHANG, Dongdong, LIU, Xuanyong a ZHANG, Yu. Recent progress in superhydrophobic coating on Mg alloys: A general review. Journal of Magnesium and Alloys. [online]. 2021. Available from: https://doi.org/10.1016/j.jma.2020.08.024.

[5] HORNBERGER, H., VIRTANEN, S. a BOCCACCINI, A.R. Biomedical coatings on magnesium alloys - A review. Acta Biomaterialia. [online]. 2012, vol. 8, no. 7, pp. 2442-2455. Available from: https://doi.org/10.1016/j.actbio.2012.04.012. 
[6] WASSERBAUER, J., BUCHTíK, M., TKACZ J., FINTOVÁ, S., MINDA J., DOSKOČIL, L. Improvement of AZ91 alloy corrosion properties by duplex NI-P coating deposition. Materials. [online]. 2020, vol. 13, no. 6, p. 1357. Available from: https://doi.org/10.3390/ma13061357.

[7] FINTOVÁ, S., DRÁBIKOVÁ, J. HADZIMA, B., TRŠKO, L., BŘEZINA M., DOLEŽAL, P., WASSERBAUER, J. Degradation of unconventional fluoride conversion coating on AZ61 magnesium alloy in SBF solution. Surface and Coatings Technology. [online]. 2019, vol. 380, pp. 125012. Available from: https://doi.org/10.1016/j.surfcoat.2019.125012.

[8] RAHMAN, Mostafizur, LI, Yuncang a WEN, Cuie. HA coating on Mg alloys for biomedical applications: A review. Journal of Magnesium and Alloys. [online]. 2020, vol. 8, no. 3, pp. 929-943. Available from: https://doi.org/10.1016/j.jma.2020.05.003.

[9] TANG, H, XIN, T Z, LUO, Y a WANG, F P. In vitro degradation of AZ31 magnesium alloy coated with hydroxyapatite by sol-gel method. Materials Science and Technology. [online]. 2013, vol. 29, no. 5, pp. 547-552. Available from: https://doi.org/10.1179/1743284712Y.0000000180.

[10] SAREMI, M., MOHAJERNIA, Sh. a HEJAZI, S. Controlling the degradation rate of AZ31 Magnesium alloy and purity of nano-hydroxyapatite coating by pulse electrodeposition. Materials Letters. [online]. 2014, vol. 129, pp. 111-113. Available from: $h$ ttps://doi.org/10.1016/i.matlet.2014.05.050.

[11] ZHANG, Min, CAI, Shu, SHEN, Sibo, XU, Guohua, LI, Yan, LING, Rui a WU, Xiaodong. In-situ defect repairing in hydroxyapatite/phytic acid hybrid coatings on AZ31 magnesium alloy by hydrothermal treatment. Journal of Alloys and Compounds. [online]. 2016, vol. 658, pp. 649-656. Aailable from: https://doi.org/10.1016/j.jallcom.2015.10.282.

[12] LI, Ling-Yu, CUI, Lan-Yue, LIU, Bin, ZENG, Rong-Chang, CHEN, Xiao-Bo, LI, Shuo-Qi, WANG, Zhen-Lin a HAN, En-Hou. Corrosion resistance of glucose-induced hydrothermal calcium phosphate coating on pure magnesium. Applied Surface Science. [online]. 2019, vol. 465, pp. 1066-1077. Available from: https://doi.org/10.1016/i.apsusc.2018.09.203.

[13] YAO, Wenhui, LIANG, Wu, HUANG, Guangsheng, JIANG, Bin, ATRENS, Andrej a PAN, Fusheng. Superhydrophobic coatings for corrosion protection of magnesium alloys. Journal of Materials Science \& Technology. [online]. 2020, vol. 52, pp. 100-118. Available from: https://doi.org/10.1016/i.jmst.2020.02.055

[14] LI, Qianqian, BAO, Xiaogang, SUN, Jin'e, CAI, Shu, XIE, Yao, LIU, Yuan, LIU, Jia a XU, Guohua. Fabrication of superhydrophobic composite coating of hydroxyapatite/stearic acid on magnesium alloy and its corrosion resistance, antibacterial adhesion. Journal of Materials Science. [online]. 2021, vol. 56, no. 8, pp. 5233-5249. Available from: https://doi.org/10.1007/s10853-020-05592-5.

[15] KANG, Zhixin, ZHANG, Junyi a NIU, Lei. A one-step hydrothermal process to fabricate superhydrophobic hydroxyapatite coatings and determination of their properties. Surface and Coatings Technology. [online]. 2018, vol. 334, pp. 84-89. Available from: https://doi.org/10.1016/j.surfcoat.2017.11.007. 